\title{
0 risco de não ir a Jerusalém. Lendo o Salmo 127 no contexto dos Salmos 120-134
}

The risk of not going to Jerusalem. Reading Psalm 127 in the context of Psalms 120-134

Osvaldo Luiz Ribeiro*

\section{Resumo}

\begin{abstract}
O tema do artigo é a análise retórica do Salmo 127 no contexto dos "Salmos das Subidas" (Salmos 120 a 134). O objetivo consiste em analisar a relação retórica possível entre o sentido da composição e o desempenho processional dos peregrinos de Jerusalém. Especificamente, trata-se de perguntar pela relação entre o conteúdo do salmo e a peregrinação para Jerusalém, a que sua leitura estaria por hipótese destinada. A metodologia consiste a) em tradução do salmo, b) análise de sua posição relativa na estrutura quiástica da coleção, c) diálogo crítico com autoridades do campo dos comentários aos Salmos d) e proposição de leitura alternativa em relação ao conjunto das leituras da literatura. Concluiuse que o Salmo 127 pode ter sido composto como alerta ou ameaça quanto ao risco de adiar-se a peregrinação a Jerusalém por força de razões que poderiam resultar na contrariedade de Yahweh, aquele que, em última análise, se não estiver contrariado, é quem garante a eficiência daquelas atividades que ora se alegariam como razões para abster-se da peregrinação.
\end{abstract}

Palavras-chave: exegese, análise retórica, salmos de peregrinação, Salmos 120-134, Salmo 127

\begin{abstract}
The theme of the article is the rhetorical analysis of Psalm 127 in the context of the "Psalms of Ascents" (Psalms 120 to 134). The objective is to analyze the possible rhetorical relationship between the sense of the composition and the processional performance of the pilgrims to Jerusalem. Specifically, it is a question of the relation between the content of the psalm and the pilgrimage to Jerusalem, to which its reading would be supposedly destined. The methodology consists in the translation of the psalm, analysis of its relative position in the chiasmatic structure of the collection, critical dialogue with the authorities of the field of commentaries to the Psalms and the proposition of an alternative reading to the other interpretations found in the literature. It was concluded that Psalm 127 may have been composed as an alert or a threat as to the risk of postponing the pilgrimage to Jerusalem for reasons that could result in the contrariety of Yahweh, the one who, ultimately, is not opposed, is the one who guarantees the efficiency of those activities that would now be claimed as reasons to abstain from the pilgrimage.
\end{abstract}

Key words: exegesis, rhetorical analysis, Psalms of Ascents, Psalms 120-134, Psalm $127^{1}$

Artigo submetido em 01 de setembro de 2017 e aprovado em 19 de abril de 2018.

*Doutor em Teologia pela PUC-Rio (2008) e Professor da Faculdade Unida de Vitória. País de origem: Brasil. E-mail: osvaldo@faculdadeunida.com.br 


\section{Introdução}

Conquanto Alonso-Schökel tenha declarado que "para compreender a fundo os Salmos, é preciso orar pessoalmente com eles" (ALONSO-SCHÖKEL, 1998, p. 718), a análise crítica e retórica dessa coleção de poemas provavelmente demanda mais aquela atitude que "na literatura especializada é frequentemente associada a termos como (...) 'agnosticismo metodológico"' (USARSKI, 2013, p. 51), ao menos porque a atitude piedosa pode funcionar como um gatilho ideológico meramente ratificador da tradição, e isso quando não chegar a servir para procedimentos políticos mais graves ${ }^{2}$. Por outro lado, reconheçamos, a intencionalidade crítica e retórica pode igualmente servir como gatilho ideológico. No entanto, dessa vez o gatilho ideológico pode ser retificador da tradição. Seja como for, não se trata de planejar-se ratificar ou retificar a tradição. Trata-se de, com ou contra a tradição, tentar recuperar a modalidade semântico-retórica original da composição, atitude teórico-metodológica de partida que poderia ser descrita ainda com os termos do último autor citado: "uma postura ideológica (...) baseada no compromisso com o ideal da 'indiferença' diante de um objeto de estudo" (USARSKI, 2013, p. 51). A despeito de que talvez se possa dizer que "os salmos são orações e como tais devem ser entendidos" (DA SILVA, 2003, p. 10), não se deve depreender daí que se precise "orar (...) com eles" para situá-los em seu contexto histórico, porque "orar com eles" é trazê-los para o mundo em que o que ora vive, ao passo que investigá-los heuristicamente é tentar o pesquisador "migrar" para o mundo de origem da composição.

Um potencial exemplo de como se pode trazer o Salmo 127 para os dias do leitor é tratá-lo como se nele se pudesse "redescobrir o valor da identidade e da missão da família segundo o projeto de Deus" (FERNANDES, 2013, p. 215), o que

\footnotetext{
${ }^{2}$ A referência é à disputada origem da famosa declaração, aqui reputada a Jomo Kenyatta, e ali a Desmond Tutu: "when the missionaries arrived, the Africans had the land and the missionaries had the Bible. They taught us how to pray with our eyes closed. When we opened them, they had the land and we had the Bible" (HUBERMAN, 2008, p. 175. "Quando os missionários chegaram, os africanos tinham a terra e os missionários tinham a Bíblia. Eles nos ensinaram a rezar com os olhos fechados. Quando nós os abrimos, eles tinham a terra e nós tínhamos a Bíblia" [em tradução livre do pesquisador]). A determinação exata de sua autoria não diminui em nada o impacto e o constrangimento que a declaração provoca, e sempre seria conveniente tê-la em mente, quando se é convidado a programas do tipo "é preciso orar primeiro". Se com a terra foi possível tão espetacular prestigiditação teológico-litúrgica, quanto mais não o seria com os sentidos históricos das composições bíblicas!
} 
se justificaria pelo fato de se estar diante da "Divina Revelação contida nos livros da Sagrada Escritura” (FERNANDES, 2013, p. 216), a qual preconiza um único tipo de família: "família heterossexual e monogâmica, como nós a conhecemos pela experiência natural e corroborada pela Divina Revelação” (FERNANDES, 2013, p. 2213). Penso não ser leviano considerar que estamos diante de um caso em que interesses teológico-pastorais, isto é, político-ideológicos, operam o programa de leitura do salmo.

Além disso, evita-se aqui tomar uma decisão unilateral em face das posições teórico-metodológicas reputadas respectivamente a Gunkel e a Mowinckel (BOSMA, 2004, p. 75; MONLOUBOU, 1996, p. 70), isto é, ter de optar entre a voz individual do salmo ou o "ambiente do culto israelita" (BOSMA, 2004, p. 75). No caso do Sl 127, deve-se evitar uma posição categórica, porque é preciso considerar com serenidade a) o fato de tratar-se de uma composição individual, b) plausivelmente situada pragmaticamente no contexto das peregrinações de Jerusalém, e c) instalada estruturalmente em uma coleção quiástica de 15 salmos. Diante desse quadro, qual das três instâncias de leitura deve prevalecer no processo hermenêutico? Qual delas deve sobrepor-se às demais? Qual delas deve reger as demais? Ora, se a composição do conjunto é secundária em relação à redação de cada poesia (KIDNER, 200o, p. 442), então se deve enfrentar pelo menos dois cenários distintos: o da composição individual e o do novo contexto de leitura que a coleção impõe à composição então organizada. Por outro lado, se a composição do Salmo 127 deu-se com vistas ao seu enquadramento na coleção dos Salmos 120124, então se estará falando de um único contexto, seja o da composição, seja o da sua instrumentalização político-teológica.

\footnotetext{
${ }^{3}$ No contexto, o autor citado distingue essa forma normativa de família "daquelas outras formas de união", definida igualmente "como família" por setores que "provocam grande mobilização pública, principalmente passeatas organizadas, para exigir de governantes e parlamentares leis que sancionem tais uniões no mesmo pé de igualdade da família heterossexual e monogâmica, como nós pela experiência natural e corroborada pela Divina Revelação" (FERNANDES, 2013, 221). Estamos diante de uma reação programaticamente conservadora às atualizações culturais e plurais da sociedade, o que se instrumentaliza por meio de uma "exegese" do Salmo 127. Você ora ou reza, lê o salmo, e, para um público que igualmente ora e reza, pode projetar nele seu reacionarismo político-cultural na forma de drágeas normativas...
} 


\section{Sobre interpretações correntes propostas para a expressão-título dos Salmos}

\section{$120-134$}

A partir da síntese que Kraus apresenta, é possível falar de pelo menos cinco

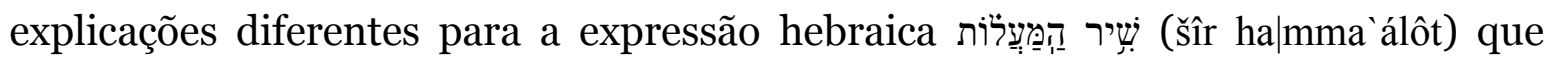
classifica cada uma das quinze composições de Salmos 120-134. A primeira explicação, de recorte literário, propõe que a expressão se refira apenas ao fato de os salmos aparecerem conectados em sequência, algo como "salmos em série" (KRAUS, 2009, p. 32). Nesse caso, não se deveria traduzir a expressão como "cântico das subidas", por exemplo, mas algo como "cânticos seriados". Kraus rejeita a explicação: "esta interpretação é demasiado formalista”, bem como não seria capaz de explicar a expressão מַעְעלוֹ (ma álôt), literalmente, "subidas” (KRAUS, 2009, p. 32).

Também de ordem literária, a segunda explicação mencionada por Kraus está relacionada ao recurso de “anadiplosis”, mecanismo retórico-literário de, no início da frase seguinte, repetir-se a última palavra da frase anterior. Há alguns casos de "anadiplosis" entre os salmos da coleção em análise, argumenta Kraus, e os indica $(120,2.3 ; 121,1.2 ; 121,3.4 ; 121,4.5$ (KRAUS, 2009, p. 32; DECLAISSEWALFORD, JACOBSON e TANNER, 2014, p. 887-888), mas acrescenta que igualmente os haveria fora da coleção, e mesmo fora do próprio Livro de Salmos, razão pela qual, acrescentando ao argumento novamente a falta de explicação para

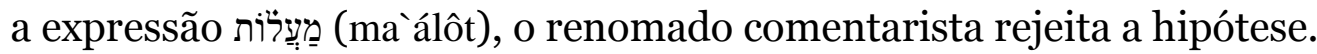

A terceira explicação que Kraus recolhe da literatura é de ordem histórica. Segundo o autor que se vem de citar, a hipótese sugere que a expressão (ma`álôt) estaria relacionada a termo que remontaria aos judaítas que retornaram do cativeiro babilônico, do que seria indício a sua ocorrência em Esdras 2,1 e 7,9. Mais uma vez, Kraus não aprova a proposta de interpretação, considerando que "é discutível se esta interpretação histórica faz justiça à característica dos cânticos reunidos nos Sl 120-134" (KRAUS, 2009, p. 32). 
A quarta e a quinta explicações vinculam a coleção ao espaço e ao ambiente cultual. A primeira delas sugeriria que o termo que designa a coleção designa igualmente a série de terraços ou degraus que permitem a alguém aproximar-se de um trono ou de um altar, e Kraus cita textos da Bíblia Hebraica que confirmariam o vínculo: 1 Re 10,19s; 2 Cr 9,18s; Ez 40,6.22.26.31.34.37.49; Ex 20,26; Ez 43,17 (KRAUS, 2009, p. 32), comentando que, nesse caso, tratar-se-iam de salmos que seriam cantados, cada um ou uma determinada série do conjunto, em um determinado degrau, passando-se ao próximo degrau para cantar os demais cânticos. Mais uma vez, Kraus rejeitará a hipótese, dessa vez alegando que a proposta comporta “certa rigidez” (KRAUS, 2009, p. 33).

Com a desconsideração dos quatro modos de interpretação anteriores, Kraus está pronto para apresentar a última modalidade, com a qual ele se identifica, posto lhe parecer "a mais razoável” (KRAUS, 2009, p. 33). A expressão-título do salmo deve ser ligada “ao verbo característico עלה" (KRAUS, 2009, p. 33), acrescentando, e esse é o ponto central do argumento, que este "é o termo técnico para designar a peregrinação" (KRAUS, 2009, p. 33), sendo indicadas como prova Sl 24,3 e 122,4. Mas haveria mais: o citado verbo estaria ligado também à ultima etapa da peregrinação, isto é, àquela etapa que liga diretamente o cortejo ao templo, “a procissão ao santuário" (KRAUS, 2009, p. 33), citando-se como testemunho 2 Sm 6; 1 Re 23,32s; 2 Re 23,1s. Disso, Kraus conclui que se poderia traduzir, portanto, a expressão-título da coleção como “cântico de peregrinação’ ou ‘cântico processional”" (KRAUS, 2009, p. 33), razão pela qual a coleção como um todo poderia ser chamada de "Cânticos das Subidas", "Cânticos de Peregrinação", "Cânticos de Romaria” ou "de Romagem” e "Cântico dos Degraus", como inclusive amiúde se pode ler nos títulos dos Salmos 120-134 versões em vernáculo.

Kraus problematiza a questão. Como, segundo considera, apenas o Sl 122 conteria de fato referências explícitas a uma peregrinação, Kraus conclui que se poderia "supor que שיר המעלות designava uma coleção de salmos a que poderíamos chamar "cantoral para peregrinações”, porém em cuja coleção se haviam “compilado também outras orações e cânticos” (KRAUS, 2009, p. 33). Não vejo 
razão para não acompanhar Kraus em sua avaliação e, inclusive, em sua posição, o que, mutatis mutandi, poderia ser expresso pelas palavras que, a respeito do Salmo 127, Agostinho emprega em seu "Sermão ao povo": “canta-o aquele que sobe com piedade e amor àquela Jerusalém do alto, pela qual suspiramos durante nossa peregrinação” (AGOSTINHO, 1998, p. 657), ou, ainda, pelas palavras de AlonsoSchökel e Carniti: “se tivermos que aceitar alguma explicação do enigmático título, a mais razoável é cantos de peregrinação" (SCHÖKEL e CARNITI, 1998, p. 1452; DECLAISSE-WALFORD, JACOBSON e TANNER, 2014, p. 887; FARIA, 2005, p. 180; SOUZA, 1994, p. 25; KIDNER, 2000, p. 442).

\section{O Salmo 127 fora do contexto dos Salmos 120-134}

Como se viu, segundo Kraus, desconsiderando-se as implicações da

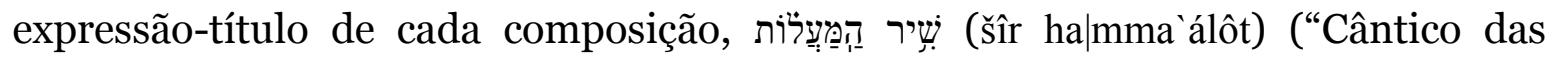
Subidas"), no corpo mesmo dos Salmos 120-134, a referência explícita à peregrinação encontrar-se-ia apenas no Sl 122 (KRAUS, 2009, p. 334). Trata-se de uma questão importante: se, cada um deles ou mesmo apenas alguns deles, os Salmos 120-134 não foram originalmente compostos para formarem a coleção, mas foram posteriormente alocados nela, então resulta necessário admitir que o contexto pragmático da leitura da respectiva composição não está originalmente vinculado às peregrinações. Por outro lado, se, como quer Kraus, "ao longo de todo o caminho de peregrinação ressoavam os cantos criados para tal eventualidade" (KRAUS, 1996, p. 100), então resulta necessário dizer que esses salmos em particular têm seu sentido original diretamente vinculado ao desempenho processional dos peregrinos de Jerusalém. No primeiro caso, o vínculo pragmáticohermenêutico entre a composição e as peregrinações ao templo é secundário, e codetermina a nova leitura do salmo apenas quando se está ciente do vínculo instrumental entre procissão e composição. Nesse caso, pode assumir que o salmo tenha sido composto já com vistas às peregrinações, ou, alternativamente, tenha

\footnotetext{
${ }^{4} \mathrm{E}$ isso a despeito de, como se verá adiante, o próprio Kraus fazer exercícios de leitura contextualizada nas rotinas de peregrinação a Jerusalém também de outros salmos da coleção (KRAUS, 1996, p. 100).
} 
apenas secundariamente sido inserido nesse contexto. Um, então, seria o sentido histórico do poema, e outro seria o novo sentido que a composição adquiria, quando recebida nesse novo contexto. Como já se viu, todavia, no segundo caso, o sentido original pretendido para a composição coincidiria com a leitura que o peregrino deve fazer da poesia.

Na prática, mesmo que cientes do fato de se estar diante de uma coleção instrumental com vistas às peregrinações religiosas a Jerusalém, os exercícios de interpretação do Sl 127 operam sem aplicar ao poema as implicações de encontrarse no contexto dos Sl 120-1345. É uma questão delicada, porque, a rigor, se o Sl 127 não foi escrito para compor a coleção, mas foi secundariamente alocado nela, então, de fato, seu sentido original não deve prestar contas à sua alocação secundária em uma coleção para a qual ele não foi originalmente concebido. Ainda que tal alocação possa gerar novo sentido à composição, a abordagem histórica não deve confundir essa reformulação com o sentido original da composição, mesmo que os dois sentidos possam eventualmente ser recuperados e analisados. Por outro lado, se a composição foi programaticamente composta para ser incluída nela, nesse caso, então, o sentido original do salmo está programática e pragmaticamente vinculado aos interesses e aos objetivos dessa coleção - nesse caso, a instrumentalização litúrgico-teológica (e política!), nas peregrinações de Jerusalém.

É preciso tomar uma decisão, e ela não é fácil. O Sl 127 foi originalmente composto para fazer parte da coleção de cânticos para a peregrinação a Jerusalém, contando então entre aqueles que Kraus considera terem sido compostos exatamente para isso (KRAUS, 1996, p. 100)? Se nos ativermos à declaração de Kraus de que, considerando os Salmos 120-134, não há nenhuma referência a qualquer tipo de peregrinação em qualquer outro salmo que não seja o $122^{6}$, e se,

\footnotetext{
${ }^{5}$ Confessando, todavia, não ter consultado a totalidade dos comentários ao SI 127 disponíveis internacionalmente, mas tendo-me servido de autores mais comumente citados e, em tese, antenados com as interpretações concorrentes, não foi possível encontrar um único caso de interpretação que vinculasse hermeneuticamente o sentido do SI 127 diretamente ao contexto processional a que o título "Cântico das Subidas" remeteria. As interpretações, como se verá, dão-se como se o Salmo 127 não constasse da coleção, a despeito de que, como também se verá, não apenas faz, mas faz de forma especial.

${ }^{6} \mathrm{Cf}$. nota 3.
} 
ao mesmo tempo, entendermos que a referência explícita a uma peregrinação seria a prova de que o salmo foi composto para uma peregrinação, então só nos restará admitir que o Salmo 127 devesse ser contado entre aqueles que, nos termos do mesmo Kraus, constituem aquelas “outras orações e cânticos” (KRAUS, 2009, p. 33), as quais, não tendo sido originalmente compostas nem para a coleção nem para a romaria, teriam sido alocadas apenas posterior e secundariamente para compor o conjunto. Nesse caso, alguém poderia concordar com Monloubou, que, a respeito do salmo que nos interessa aqui, expressou a seguinte declaração: "nem todos os salmos remetem tão claramente à liturgia: por exemplo, que nexo com o culto pode-se ver em salmos como (...) 127?” (MONLOUBOU, 1996, p. 70).

Como se disse, é delicada a questão. Todavia, talvez deva significar algo mais do que mera posição relativa no conjunto, o fato de que o Sl 127 ocupe a posição central na estrutura da coleção. Nem Kraus nem Weiser, os dois autores mais utilizados nesse exercício, tocam no assunto, mas uma obra secundariamente utilizada menciona explicitamente o fato de que, oitavo salmo da coleção, o salmo “de Salomão” ocupe o meio da estrutura (BRUEGGEMANN e BELLINGER, 2014, p. 542). Há mesmo quem chegue a falar na função de pivô que o Salmo 127 exerceria na coleção (MCCANN, 1996, p. 1.197). Com efeito, do 120 ao 134, todos os salmos recebem um mesmo título: שִִׁיר (šîn ha|mma`álôt) ("Cântico das Subidas”). Fosse, todavia, apenas esse título que cada composição recebesse, deveríamos concluir pela absoluta simetria quanto à relevância e ao papel de cada poema: se todos recebem o mesmo título, é porque, considerando-se o conjunto, o papel de cada composição é proporcionalmente o mesmo. Todavia, alguns desses quinze salmos recebem outros títulos. São apenas cinco dentre eles. Desses cinco, quatro recebem um segundo título, além daquele próprio de cada um dos quinze salmos da coleção. Os Sl 122, 124, 131 e 133 recebem um segundo título לְְִ?

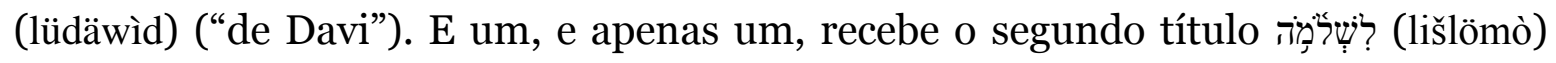
(“de Salomão”). Esse único salmo é o Sl 127. O fato de que o Sl 127 é o único dentre

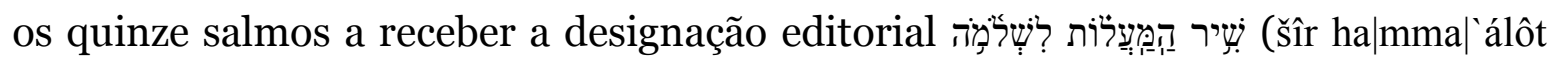
lišlömò) ("Cântico das subidas. De Salomão”) deve significa alguma coisa. 
Por que, dentre todos os quinze salmos, justamente o Sl 127 recebe essa designação? Mais, se o único salmo que faz referência explícita à peregrinação é o Sl 122, por que não é esse, mas o 127, que recebe a designação diferenciada "de Salomão"? Mais do que isso. A designação especial “de Salomão” não é um dado isolado, mas, como antecipado acima, a posição que o Sl 127 recebe no conjunto dos "Cânticos das Subidas" é reveladora, mais uma vez, da excepcionalidade que se concedeu a essa composição. A organização dos salmos na coleção é de tal ordem que dois dos salmos designados “de Davi” compõem molduras superiores ao salmo central, e os outros dois, as molduras inferiores. E, sim, uma vez que se pode falar de "molduras", é porque se está diante de uma estrutura "quiástica”. A essa altura, não se espera que se encontre no núcleo do "quiasmo" outro salmo que não o Sl 127, como, de fato, se pode facilmente visualizar:

\begin{tabular}{|c|c|c|}
\hline 120 & 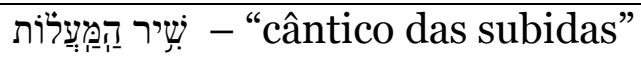 & \\
\hline 121 & 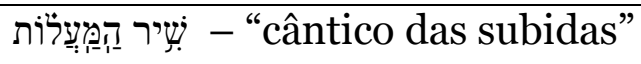 & \\
\hline 122 & 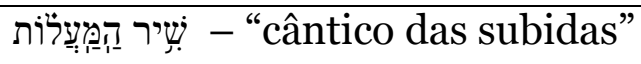 & - לְִּונד - de Davi \\
\hline 123 & 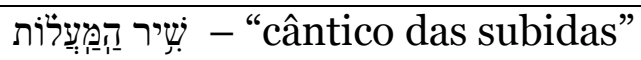 & \\
\hline 124 & 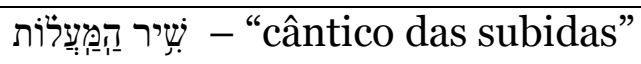 & 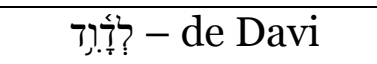 \\
\hline 125 & 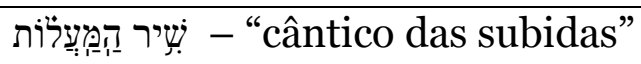 & \\
\hline 126 & 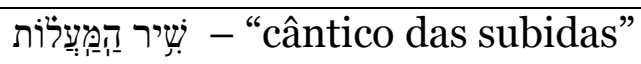 & \\
\hline 127 & 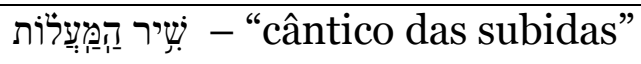 & 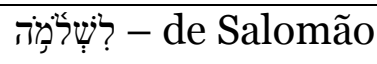 \\
\hline 128 & 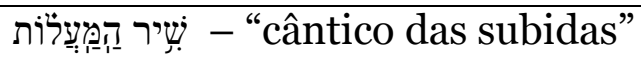 & \\
\hline 129 & 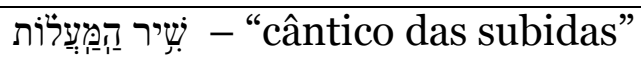 & \\
\hline 130 & 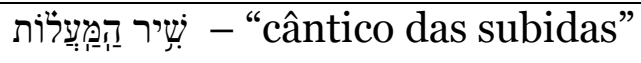 & \\
\hline 131 & 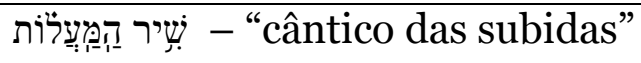 & 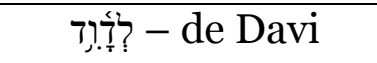 \\
\hline 132 & 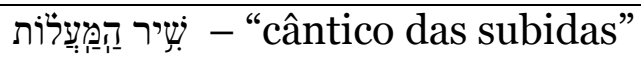 & \\
\hline 133 & 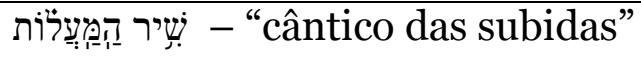 & - לִדְונד - de Davi \\
\hline 134 & 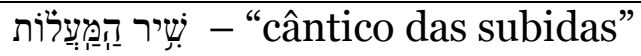 & \\
\hline
\end{tabular}

O Salmo 127 não é apenas o salmo que, na coleção, recebe o único título

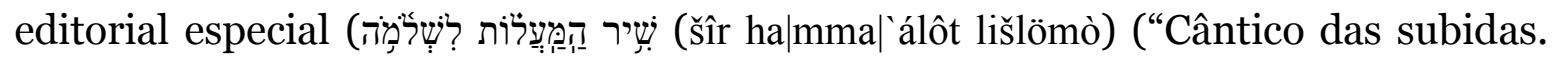


De Salomão”), mas, recebendo esse único título editorial, esse único salmo “de Salomão" na estrutura é ainda o salmo central do quiasmo que governa a organização da coleção. A concomitância do título editorial diferenciado (certamente por força de ser o salmo central) e da posição central do salmo na estrutura impõe ao Sl 127 uma posição igualmente diferenciada e especial no conjunto.

Um famoso comentarista dos Salmos, Weiser, desconsidera categoricamente que a designação do Sl 127 com o nome do rei construtor do templo de Yahweh indique alguma relação necessária entre o salmo e o mesmo templo de Jerusalém (WEISER, 1994, p. 596), preferindo considerar que o salmo componha "parte do mundo intemporal do provérbio" e a "peculiaridade dos ditos sapienciais" (WEISER, 1994, p. 5967), constituindo cada uma das assim por ele assumidas duas partes do salmo como "dito sapiencial” (WEISER, 1994, p. 597-598), sendo que a atribuição ao nome de Salomão deva ser assumida "quiçá porque era considerado o autor da sabedoria do Antigo Testamento" (WEISER, 1994, p. 596). Por sua vez, o já mencionado Kraus considera que o título especial que o salmo recebeu, "de Salomão”, decorra de uma interpretação do motivo da construção da casa, no v. 1, lida então como referência à construção do templo de Jerusalém (KRAUS, 2014, p. $669)^{8}$.

Estes são exemplos claros de que a presença do salmo na coleção dos “cânticos das subidas" e o título especialíssimo que ele recebe pelos editores da coleção podem não significar absolutamente nada para os comentaristas, com o que me refiro ao fato de que não se percebe vínculo ideológico entre a composição

\footnotetext{
${ }^{7}$ Nesse particular, Weiser não está sozinho. Kraus afirma que "por seu estilo" o Salmo 127 deve ser identificado com "o gênero literário da poesia sapiencial" (KRAUS, 2014, p. 668; KUNTZ, 1974, p. 189).

${ }^{8}$ STOCKS, 2012, p. 126. Um autor que se cita pela primeira vez aqui, considera que o fato de o título levar o nome de Salomão "permitiu interpretar a casa como o Templo", fator que o leva a interpretar a composição como peça pós-exílica, cuja mensagem se resumiria à proposição de que "após o cativeiro, somente Yahweh pode construir a morada há muito destruída" (CHOURAQUI, 1996, p. 333). Além disso, pode-se ao mesmo tempo apontar para a dupla vinculação entre o título "de Salomão" e, de um lado, as tradições sapienciais e, de outro, a construção do templo (BRUEGGEMANN; BELLINGER, 2014, p. 542). Como se dirá mais à frente, talvez se devesse considerar que a vinculação seja realmente ao templo, mas não à sua construção, mas ao fato de se tratar de um salmo programaticamente vinculado ao uso processional nas peregrinações àquela casa sagrada. Num outro extremo, um autor que tem uma opinião bastante curiosa sobre a razão do título "de Salomão" propõe que se deva ao fato do tríplice "em vão", que o ligaria a Eclesiastes e sua teologia da "vaidade" (PHILLIPS, 2002, p. 482). Mas nenhuma explicação parece mais curiosa do que aquela que conclui dever-se a relação pelo fato de ter o salmo sido composto pelo próprio Salomão (DAHLBERG, 2007, p. 76).
} 
em si e as peregrinações para o templo. Ora, se, de um lado o nome de Salomão pode ser evocado para indicar tradições sapienciais, por outro lado, tomado como sendo as peregrinações para o templo, o contexto pragmático da coleção deveria pelo menos por em discussão o vínculo ideológico entre o salmo, o título “de Salomão" e as viagens processionais para Jerusalém. Deve-se concordar com Weiser e com Kraus quanto ao fato de que a referência à construção em Sl 127,1 não deva necessariamente ser tratada como uma referência à (re)construção do templo de Jerusalém, de sorte que construir a casa significasse na verdade a construção do templo. Todavia, isso não significa que, se a construção da casa, em si, não se refira à construção do templo, então não pode haver nenhuma relação entre o salmo e o templo, relação potencial que até mesmo Agostinho havia percebido, posto que vincula o título do salmo à tradição de ter sido Salomão o construtor do templo (AGOSTINHO, 1998, p. 658). Além disso, nem Weiser nem Kraus consideram que o título "de Salomão" não pode ser um dado isolado da coleção, mas constitui o núcleo de uma estrutura dificilmente não proposital, na qual outros quatro salmos recebem o título “de Davi”. Note-se que, para alegar que o Sl 127 teria recebido o título "de Salomão" devido à secundária identificação da construção da casa no v. 1 com a construção do templo, Kraus empregou a expressão "seguramente" (KRAUS, 2014, p. 669). A despeito disso, talvez se deva considerar não tão segura assim a questão, porque, na coleção, o título “de Salomão” não é um dado isolado, mas constitui elemento estrutural compartilhado com outros quatro salmos, dessa vez classificados como “de Davi”, os quais lhe funcionam como dupla moldura. Sendo assim, não se considere necessário buscar explicações na história dos efeitos dos respectivos salmos para justificar tais títulos. Talvez se devesse considerar que tanto o título “de Davi” (Salmos 122, 124, 131, 133), quanto o título "de Salomão” (Salmo 127) não se devessem a nada de particular na história da recepção dos respectivos salmos, mas antes ao fato de, já na origem, ou, alternativamente, no momento da organização da coletânea, constituírem esses salmos marcos estruturais na organização de uma coleção intencionalmente elaborada e programada para o uso litúrgico nas romarias ao templo de Jerusalém. Não coincidentemente, a construção desse templo foi tradicionalmente remontada a 
Salomão, mas não sem os significativos esforços de Davi, razão pela qual os marcos estruturais da coleção levariam justamente esses dois nomes. Nesse caso, ao contrário da opinião de Weiser e Kraus, e, em certa medida, em relativa conformidade com a opinião de Agostinho, ao lado do de Davi, o nome de Salomão estaria ligado diretamente ao contexto de uso da coleção, a peregrinação ao templo de Jerusalém, e não a alguma particular expressão do conteúdo, então apenas secundariamente atualizada.

Seja como for, o modo como Weiser, e mesmo Kraus, interpreta o salmo é característico daquela abordagem que, informada ou não, e concordando ou não com a relação entre o salmo e as peregrinações ao templo, no ato concreto de sua interpretação, na prática o isolam do referido contexto. No caso de Weiser, declarado dividido o salmo "em duas partes que absolutamente não se relacionam” (WEISER, 1994, p. 5969), v. 1-2 e v. 3-5, a interpretação que se dá aos v. 1-2 é que se trata de admoestação para que se tenha "confiança e fé em Deus" (WEISER, 1994, p. 597), e a interpretação que se dá aos v. 3-5 resulta em declarar "os filhos como dom confiado por Deus" (WEISER, 1994, p. 598). Nenhuma problematização. Nenhuma pergunta sobre por que um tipo tão ameno de discurso teológico-sapiencial estaria posicionado no núcleo de uma coleção cuja função precípua é servir de roteiro litúrgico para as romarias ao templo.

Por outro lado, chama atenção o fato de que algumas declarações do salmo são vistas por Weiser como indicativo de algo “sombrio e sinistro" (WEISER, 1994, p. 596). Mas o comentarista citado não há de extrair dessa percepção - a meu ver, acertada - nenhuma conclusão que interfira em sua interpretação teológicopastoral. Eis as palavras de Weiser: “o tríplice 'em vão', que se pronuncia sobre o agir dos homens que prescindem de Deus, soa um tanto sombrio e sinistro" (WEISER, 1995, p. 596). E eis sua conclusão: “essa atitude não procede da fé, estando, em consequência, sob o juízo de Deus. A ideia de que o homem poderia fazer tudo sozinho nasce da desconfiança em Deus e de falsa confiança em si”

\footnotetext{
${ }^{9}$ Já se propôs tratar-se de um salmo composto por dois salmos originais independentes (ZORN, 2004, p. 420; MILLER, 1982, p. 119).
} 
(WEISER, 1994, 597). Weiser reduz o salmo a uma discussão sobre virtudes teologais. Nenhuma pergunta sobre por que essa discussão nessa coleção. O que é uma pena, porque o que há de "sombrio e sinistro" no salmo pode derivar exatamente do fato de que se trate do salmo central da composição elaborada para uso nas peregrinações ao templo de Jerusalém.

A leitura que Kraus oferece não fica muito distante do tipo de leitura que acabamos de ver. Aliás, talvez se possa dizer que, comparativamente a ela, é menos ainda “desconfiada”. Em Kraus, não se vai encontrar a observação da presença de algo "sombrio e sinistro" no Sl 127. Para o comentarista, a finalidade do salmo é assentar categoricamente a declaração da total incapacidade humana de fazer qualquer coisa sem a ajuda divina: "todos os esforços e preocupações do homem que se realizam à margem (...) [de Yahweh] são vãos” (KRAUS, 2014, 672), porque "o homem vive da presença de Deus (...). Seu futuro depende única e exclusivamente da generosidade de Yahweh" (KRAUS, 2014, 672). Nenhuma, absolutamente nenhuma referência à peregrinação ao templo de Jerusalém...

\section{O Salmo 127 no contexto dos Salmos 120-134}

Eis o que acima foi demonstrado: o Sl 127 a) é uma das composições da coleção dos "Cânticos das Subidas", b) é o único salmo que, na coleção, recebe o título especial "de Salomão", e c) é ainda o salmo central da coleção quiástica plausivelmente reunida para serem cantados os seus cânticos durante a peregrinação para o templo de Jerusalém. Qual a implicação de o que foi demonstrado ter relação direta com o fato de a coleção, e, por isso, o Sl 127, ter sido formado especificamente para esse fim - a peregrinação a Jerusalém? E se a chave de leitura do Sl 127 se encontrar justamente no seu vínculo com as peregrinações para a cidade do templo? E se não estivermos diante de preceitos sapienciais, atemporais, mas diante de recomendações muito específicas, cujo sentido se esclarece se compreendidas no contexto das peregrinações? Como se comporta aquele algo de "sombrio e sinistro" que Weiser percebeu no salmo, quando ele é 
lido no contexto das peregrinações? E se as peregrinações são a razão de ser do Sl 127, seu conceito-chave, seu locus hermenêutico?

Evidentemente, não se poderá concluir de forma indiscutível que esse seja o caso. Trata-se de serenamente considerar a plausibilidade da hipótese, que tem em sua defesa pelo menos os três argumentos que abrem a presente seção. Justifica-se, portanto, pelo menos um exercício de leitura do salmo, tomado como programaticamente vinculado ao contexto das peregrinações de Jerusalém.

Com esse objetivo em mente, portanto, e com base no texto massorético da Bíblia Hebraica, é hora de analisar o próprio salmo.

\begin{tabular}{|c|c|c|}
\hline \multicolumn{3}{|c|}{ Salmo $127^{10}$} \\
\hline 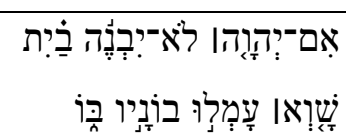 & 1a & $\begin{array}{l}\text { Se Yahweh não constrói a casa, } \\
\text { em vão trabalham os que a constroem! }\end{array}$ \\
\hline 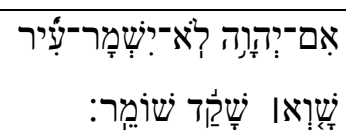 & $1 \mathrm{~b}$ & $\begin{array}{l}\text { Se Yahweh não guarda a cidade, } \\
\text { em vão vigia a sentinela! }\end{array}$ \\
\hline 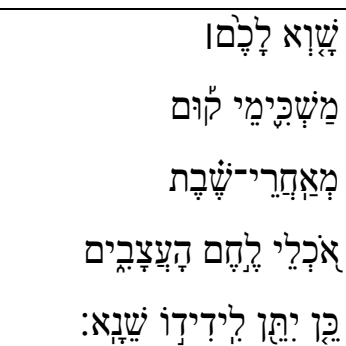 & 2 & $\begin{array}{l}\text { É em vão para vós } \\
\text { madrugados se levantarem, } \\
\text { pernoitados se deitarem, } \\
\text { alimentados do pão dos esforços, } \\
\text { pois dá aos seus amados que dormem. }\end{array}$ \\
\hline 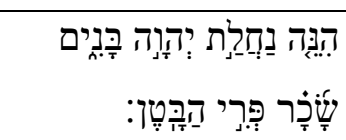 & 3 & $\begin{array}{l}\text { Eis que herança de Yahweh são os filhos, } \\
\text { uma recompensa, o fruto do ventre. }\end{array}$ \\
\hline 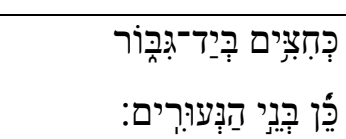 & 4 & $\begin{array}{l}\text { Como flechas na mão do guerreiro, } \\
\text { assim são os filhos da juventude. }\end{array}$ \\
\hline 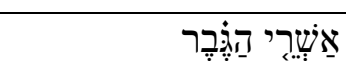 & 5 & Feliz é o homem \\
\hline
\end{tabular}

${ }^{10}$ Para as questões crítico-textuais, Kraus (2014, p. 667-668). 


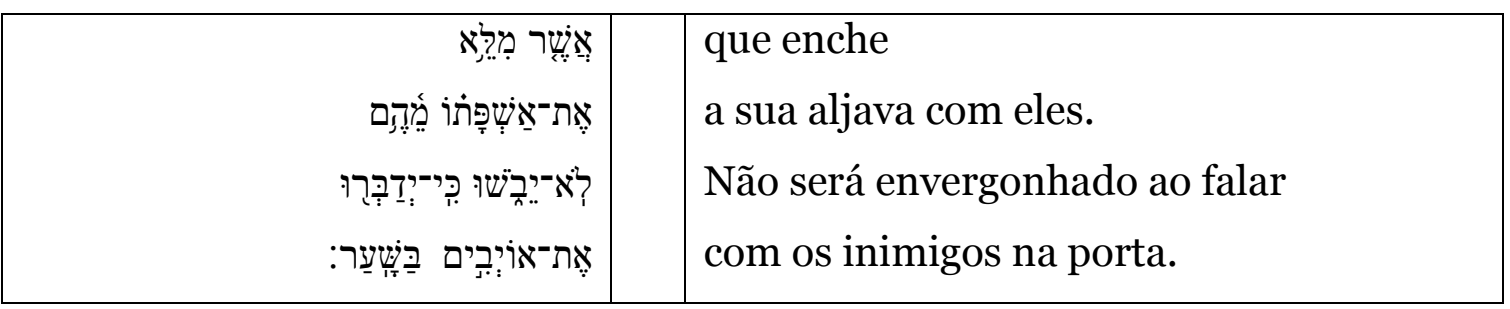

A despeito da opinião de Weiser, não se deveria considerar que, sejam quantas forem, não haja relação entre as partes do salmo (WEISER, 1994, p. 596; MILLER, 1982, p. 11911). O fato de Weiser não enxergá-las não significa, necessariamente, que não existam. A questão é encontrar a chave de leitura que permita intuir a relação possível entre cada uma das quatro assertivas da composição. Kraus, por exemplo, é de opinião que "há uma conexão bastante profunda que une as duas seções" (KRAUS, 2014, p. 668).

O salmo está dividido não proporcionalmente em quatro assertivas (KRAUS, 2014, p. 668), três delas marcadas pelo termo ocupando os versos 1-2, e a última, ocupando todos os v. 3-5, tratando do tema dos filhos como "herança de Yahweh". Considerando-se as dimensões da composição, os três temas dos v. 1-2 ocupam proporcionalmente o mesmo espaço que o tema dos filhos como herança divina, dos v. 3-5. Dos três temas dos v. 1-2, dois parecem muito claros, e o terceiro é um pouco mais difícil de captar. Trata-se dos temas da construção da casa (v. 1a), da vigilância e da defesa da cidade (v. 1b) e da colheita e do preparo do pão (v. 2), ou, como percebem Alonso-Schökel e Carniti, o "dom agrário" (SCHÖKEL e CARNITI, 1998, p. 1499), ou ainda, como percebeu Zorn, a "alimentação essencial" (ZORN, 2004, p. 421). Assim, em série, os quatro temas do salmo seriam a construção da casa, a defesa da cidade, a colheita da lavoura e o nascimento de um filho (KRAUS, 2014, p. 668).

Qual a relação possível entre esses temas e a função dos "Cânticos das Subidas"? Por que alguém que está indo a Jerusalém precisa cantar que, "se Yahweh não construir a casa, inútil trabalham os que a constroem”? Ou qual a

\footnotetext{
${ }^{11}$ As questões relativas à discussão sobre a unidade do Salmo 127 poderiam ser acompanhadas pelo citado artigo de Miller, cujo foco é exatamente discutir a unidade da composição.
} 
razão que os peregrinos teriam para, indo em romaria, cantar "se Yahweh não guardar a cidade, inútil é vigiar a sentinela”? O mesmo vale perguntar sobre as outras duas questões do salmo, a colheita e o nascimento de um filho: por que cantar isso nesse contexto pragmático?

De pronto, convém antecipar uma eventual resposta: canta-se em gratidão. O peregrino reconhece a ação de Yahweh e, grato por isso, celebra o que, por exemplo, Kraus considera ser a “generosidade de Yahweh” (KRAUS, 2014, 672). Não é uma hipótese descabida. Todavia, não há qualquer referência à gratidão no texto. Nenhum elogio à divindade, nenhuma palavra de reconhecimento por algo feito. Nada de "bendito seja Yahweh que nos constrói a casa", ou "bendito seja o deus que nos dá o pão”. Antes, a composição inteira se caracteriza pela declaração categórica da exclusividade da ação de Yahweh, paralelamente ao que vai a declaração de absoluta inutilidade do peregrino - e isso em face justamente da peregrinação. Não parece se tratar de um salmo que agradeça por ações passadas de Yahweh, mas um salmo que quer garantir justamente as ações futuras. O salmo tem em vista a construção da casa, a proteção da cidade, a colheita e o pão à mesa, o nascimento dos filhos, mas não põe em perspectiva de passado nenhuma dessas "bênçãos". Pelo contrário, o salmo insiste em que o logro de cada uma das referidas ações depende única e exclusivamente de Yahweh, e não dos agentes humanos seus beneficiários, aspecto que Kraus considera de máxima relevância para o salmo (KRAUS, 2014, p. 672).

Se parece razoável supor que haja uma ligação indissociável entre o fato de alguém ter de ir a Jerusalém e cada uma das assertivas mencionadas, e se não se pode atribuir à retórica da composição um espírito de gratidão por bênçãos alcançadas, deve-se então perguntar mais uma vez pela relação entre as declarações do salmo e o contexto instrumental da composição. Parece razoável, então, considerar que a relação esteja no fato de que cada uma das assertivas aponta para potenciais e justificadas razões para o peregrino deixar de ir a Jerusalém. 
Apenas a título de analogia, conviria fazer referência à "parábola da grande ceia”, localizada em Lucas 14,15-24. No contexto de uma grande ceia oferecida a determinados convidados, cada um deles apresentou uma justificativa para escusar-se de comparecer. Um teria adquirido um terreno e carecia de ir vê-lo. Outro argumenta que havia recém adquirido uma junta de bois, e era necessário tomar as providências para acomodá-los. Um terceiro alegou que havia se casado e, compreensivelmente, não podia ir. Tomando ciência, então, das desculpas alegadas, o anfitrião instrui a seu servo que ofereça o banquete a outras pessoas. Para o que interessa à analogia que aqui se tem em mira, importa observar que os convidados, ou seja, aqueles que deveriam ir ao banquete, têm a seus próprios olhos justificadas razões para não ir ao banquete. Não vem ao caso que em Lucas o desenrolar da cena se dê de forma completamente diferente da forma como ela se desenvolve no Salmo 127. Com efeito, o anfitrião não dirá absolutamente nada nem nada fará para demover seus convidados de sua posição de recusa. No caso do Salmo 127, todavia, os organizadores das peregrinações, os diretamente interessados nelas, simplesmente não estão dispostos a condescender com os peregrinos que, da mesma forma como os convidados da parábola, apresentam argumentos muito compreensíveis para não participarem da viagem. Os organizadores elaboram uma estratégia retórica para, ao contrário do anfitrião da parábola de Lucas, fazer com que os peregrinos, mesmo que com todas as razões para não ir a Jerusalém, entendam que devem ir.

Experimentemos a hipótese diretamente no salmo agora. Analisemos cada uma das assertivas apresentadas na composição. Primeiro: aquele que deve ir a Jerusalém tem uma justificativa para adiar a peregrinação: está construindo uma casa, sua casa, presumivelmente. Kraus entende que "casa” aí é a família: "em sentido muito amplo, a criação de uma família” (KRAUS, 2014, 669). Mas Kraus não discute a razão pela qual o verbo “construir" é empregado, além do que, depois de ter proposto que a expressão "construir uma casa" fosse considerada, na verdade, "estabelecer uma família”, sugere que a declaração seguinte, "guardar a cidade”, signifique, de novo, proteção a esta mesma família. Para poder tratar o v. 1 como referência apenas à família, Kraus amplia o sentido da expressão "construir 
uma casa" ao mesmo tempo em que reduz o sentido da expressão "guardar a cidade", quando seria mais natural deixar que a expressão "construir uma casa" significasse isso mesmo, construir uma casa, bem como deixar que a expressão "guardar a cidade" não fosse outra coisa do que isso mesmo, guardar a cidade. Tratando-se, pois, a expressão a partir de seu sentido mais direto, “construir uma casa”, convém ressalvar que, todavia, não se trata de um trabalhador que, por força de ter uma encomenda, deve adiar a viagem obrigatória, mas possivelmente de um homem que, estando a construir a própria casa, onde deve morar, plausivelmente, ele e a família, não pode, por isso, dirigir-se à cidade do templo. Ter que dedicar tempo à construção da (própria) casa parece uma razoável justificativa para adiar para a próxima vez a peregrinação ao templo...

A segunda questão pode facilmente assumir os mesmos contornos de justificativa para não se ir à romaria. A viagem não é de poucas horas. São dias investidos. A cidade onde se reside corre o risco de ficar desprotegida, e muitos são os bandoleiros e assaltantes, sempre à espera de oportunidade. Alguém pode considerar que a vigilância de uma vila, a proteção de uma cidade, sejam razões suficientes para que alguém se sinta desobrigado de não se dirigir à Jerusalém, tanto quanto ter adquirido uma junta de bois e ser preciso alojá-la é razão compreensível para ausentar-se do banquete.

A terceira assertiva parece apontar para o calendário das colheitas. Nesses momentos, o tempo é fundamental. Não se pode colher nem antes nem depois do tempo conveniente. Por força disso, o trabalho deve começar mais cedo do que de costume, e deve terminar mais tarde do que o normal, de sorte que é muito o trabalho e as exigências são urgentes, sem cujo trabalho árduo e intenso não se pode, amanhã e depois, comer o pão que se deve por à mesa. Em épocas assim, o camponês pode sentir-se mais do que justificado, e não considerar seriamente a necessidade de dirigir-se ao templo de Yahweh.

Finalmente, ocupando metade das dimensões do salmo, encontra-se a assertiva de serem os filhos a herança de Yahweh. Se a intuição hermenêutica de 
que se está diante do tema do nascimento de mais um filho na casa estiver correta, então a chave de leitura do salmo 127 se conclui: um homem acaba de receber mais um filho em sua casa, o bebê ainda chora no colo da mãe, e essa parece razão suficiente para adiar para ano que vem a viagem que se deveria fazer amanhã ainda.

No conjunto, aquilo que parecia totalmente alheio ao contexto das peregrinações assume uma impressionante proximidade referencial. Podem-se tratar as quatro declarações do Salmo 127 como referências a justificativas para adiar a peregrinação: o potencial peregrino está considerando postergar a romaria por um desses quatro motivos, todos muito nobres e justificáveis: está construindo sua casa, precisa vigiar a cidade, está em época de colheita e precisa receber o mais novo nascituro da família. Como os convidados da parábola, os potenciais peregrinos têm outras urgências em mente.

Se, sempre por hipótese, a chave de leitura foi identificada, não se pode negligenciar o fato de que, em nenhuma hipótese, é o próprio peregrino a falar no salmo. No salmo, fala a voz dos organizadores jerosolimitanos das peregrinações. Com o objetivo de recolher os argumentos amiúde empregados no esvaziamento das caravanas de peregrinos, os compositores do Sl 127 elaboram "respostas" teológicas - para citar os termos de Weiser, "sombrias e sinistras" -, para cada tentativa de justificar o adiamento da viagem.

Tomado então como resposta sacerdotal ${ }^{12}$ às potenciais justificativas dos camponeses para não irem a Jerusalém¹3, deve-se admitir que o Salmo 127 não

\footnotetext{
12 O SI 127 é o salmo central da composição quiasmática formada como cancioneiro para as peregrinações ao templo de Jerusalém. Parece justificada a proposição de que, por isso, deva a composição, que atende a interesses do templo de Jerusalém, ser classificada como sacerdotal. Aliás, sua classificação como composição sacerdotal permaneceria mesmo no caso da inversão da proposta de leitura: em lugar de tratar-se de ameaça ao peregrino, tratar-se-ia de uma composição para reforço positivo. Ora, ameaça quanto a não se peregrinar a Jerusalém ou reforço positivo para se peregrinar a Jerusalém, nos dois casos, é justificado conceber que os interesses diretos de ambos os casos é sacerdotal.

${ }^{13}$ Deve-se ter em mente que a retórica da composição pode constituir o caminho que reta ao compositor em face das desculpas que o peregrina apresenta como justificativa para não empreender a peregrinação. De um lado, não são desarrazoadas. Se fossem, bastaria o compositor redigir uma advertência à falta de razão. Não é o caso. Por outro lado, se fossem argumentos atípicos, desconhecidos da tradição consuetudinária, bastaria ao compositor apontar para o inusitado dos argumentos, bem como para sua condição de pleitos não tipificados na tradição. Não é ocaso. Resta ao compositor, diante da razoabilidade e da tipificação tradicional dos argumentos, advertir ao peregrino que quer se furtar ao seu dever que desagradar ao deus do templo de Jerusalém pode ter consequências contrárias às expectativas do recalcitrante peregrino: as bênçãos que ele agora usa como desculpas para não ir à peregrinação podem simplesmente desaparecer. Pelo sim, pelo não, é melhor não arriscar...
} 
desautoriza os argumentos empregados nas justificativas. O Salmo 127 não diminui em nenhuma medida nenhuma das alegações potenciais. Tomem-se cada uma das respostas e fica evidente que os sacerdotes chegam mesmo a concordar com as alegações. Na verdade, provavelmente apenas se servem das próprias justificativas apresentadas para, empregando-as como arma retórica contra os próprios peregrinos, demovê-los de sua posição e movê-los em direção ao templo.

Primeiro, os redatores do salmo concordam que Yahweh interessa-se pessoalmente pela construção das casas de seus "amados". Na verdade, é o que o v. 1 diz, nem são os construtores que constroem: é o próprio Yahweh. Se os construtores trabalham na construção, e Yahweh trabalha na construção, então o trabalho dos construtores não é inútil. Até aqui, pode-se citar um dos comentaristas já citados: "toda atividade é 'vã (...)' se Yahweh mesmo não está presente para por os fundamentos e construir o edifício" (KRAUS, 2014, 669). No fundo, é Yahweh quem trabalha. Mas, e se os trabalhadores trabalham, mas Yahweh, não? Com efeito, é inútil que os trabalhadores trabalhem, se Yahweh não trabalhar...

Segundo, Yahweh tem interesse direto na proteção das cidades de seus amados. Se os próprios amados vigiam-na, colocam sentinelas aqui e ali, isso não significa que sejam elas, as sentinelas, as responsáveis efetivas pela vigilância da cidade. Porque, enquanto as sentinelas vigiam, é o próprio Yahweh quem efetivamente vigia e guarda a cidade. As sentinelas acham-se ciosas de seu trabalho, e, de fato, se Yahweh está com elas, então sim é de extrema importância seu labor. Todavia, é totalmente inútil que vigiem a cidade (KRAUS, 2014, 669), se Yahweh não a vigiar...

Terceiro, a colheita. Se Yahweh se preocupa e mesmo trabalha a própria construção da casa dos amados, e se Yahweh pessoalmente guarda a cidade, como não estaria ele, pessoalmente, envolvido na alimentação de seus amados? Ainda que os camponeses estiquem o dia, para trabalhar até muito mais tarde, e ainda que os lavradores antecipem o dia, para trabalhar desde muito mais cedo, porque 
precisam trabalhar muito e duramente para colher arduamente o pão do ano inteiro, quem efetivamente os alimenta, e isso não enquanto trabalham, mas enquanto dormem, é Yahweh. Naturalmente que isso significa abençoar o trabalho duro que é o trabalho de plantar e de colher, de colher e de preparar o pão, o que de fato Yahweh abençoa, pão que realmente vai para a mesa dos lavradores, se Yahweh o der enquanto dormem...

Finalmente, por último, mas, de longe, não o menos importante, a chegada de um novo filho ao lar. Claro que se trata de uma alegria. Que ninguém pense, por um minuto, que não se entende a relevância desse momento teológico: os filhos são dados por Yahweh, são seu dom, sua herança. O homem que tem muitos desses dons divinos é como o guerreiro que tem a mão cheia de flechas. Quando tiver que resolver problemas de toda ordem, que envolvam o litígio na porta da cidade, a chegada dele e de sua nuvem de flechas levarão os anciãos a abençoá-lo com a vitória processual, para sua alegria, e tristeza de seus inimigos. Sim, os filhos são dádiva e dom, mas é Yahweh quem os dá, se os dá...

Ora, se aceitarmos a conclusão de Alonso-Schökel e Carniti de que "podemos considerar esse salmo como oração de confiança em Deus, expressa em termos negativos e positivos: 'sem Deus é inútil... mas Deus dá”" (SCHÖKEL e CARNITI, 1998, p. 1498), então teremos deixado escapar que, a rigor, o salmo não afirma, categoricamente, que "Deus dá”: a composição está suspensa sobre o inexorável tempo-modo condicional: se Yahweh não, então em vão. Convenhamos que haja formas mais claras, diretas e inequívocas de se dizer "Deus dá”, declaração que, nesses termos, o Salmo 127 não faz. Tudo aí é condicional. Tudo o que Yahweh tem a dar está inexoravelmente preso a uma condição. É preciso, portanto, avaliar mais detidamente a retórica da composição.

Isoladas do contexto do cântico, cada uma dessas declarações pode ser tomada como uma assertiva teológica positiva, no campo da doutrina pastoral: Yahweh abençoa os seus amados, construindo para eles as suas casas, protegendo para eles as suas cidades, providenciando para eles o pão diário e enchendo sua 
casa de filhos. Todavia, o contexto em que tais declarações são feitas, e, ainda mais, aquele tríplice “'em vão’, que se pronuncia sobre o agir dos homens que prescindem de Deus, (que) soa um tanto sombrio e sinistro" (WEISER, 1994, p. 596) sugeremnos, para não dizer obrigam-nos a conceder atenção mais crítica ao enunciado. A ênfase está justamente nesse “em vão”, nesse “inútil”, e, instalado no contexto da obrigação da romaria ao templo, o tom “sombrio e sinistro" denunciado tão cautelosamente por Weiser revela-se com cores ainda mais sombrias e sinistras do que se pode ter considerado.

É que o Salmo 127 concorda com cada uma das justificativas, apenas e tão somente para usá-las contra o próprio peregrino que ameaça adiar a romaria. $\mathrm{O}$ raciocínio estampado em cada seção do salmo é bastante simples e, salvo melhor juízo, muito claro. Considerar que se está desculpado de ir a Jerusalém, porque se está construindo uma casa é realmente pertinente. Há um problema aí, todavia. O peregrino considera que a sua casa há de ser construída por ele, o próprio peregrino. Com efeito, se é ele que constrói a casa, ele não pode ir. Se ele for, quem construirá a casa? No entanto, o peregrino comete um erro teológico grave: ele acha que é ele que constrói a casa. "Providencialmente", o Salmo 127 lembra ao peregrino que não é ele quem a constrói de fato, mas Yahweh. O cerne da questão, a enunciação, o que se quer efetivamente dizer aí está nisso: é Yahweh quem constrói sua casa, não você. E o que isso significa, se se põe tal declaração no contexto da coleção dos "cânticos das subidas" e se considera que o salmo esteja reagindo às justificativas dos peregrinos de esquivar-se da viagem? Significa que, ofendido pelo fato de o peregrino escusar-se de ir a sua casa, quem sabe Yahweh deixe de construir a casa do peregrino, e, dado que é Yahweh quem de fato constrói, e não o peregrino, seja inútil ao romeiro ficar em sua cidade para construir sua casa, porque, se Yahweh, ofendido, recusar-se a construí-la, então a casa jamais será construída, ainda que o peregrino falte a uma centena de peregrinações. É muito mais sábio ir a Jerusalém, porque assim Yahweh ficará satisfeito e trabalhará ele mesmo, como sempre fez e faz, se não estiver ofendido, na construção da casa de seu amado... Evite-se o risco. Faça-se peregrino. 
A chave de leitura é, portanto, nos termos da presente proposta heurística, a ameaça teológica. Em face de recusarem-se a viajar os potenciais peregrinos, o salmo recolhe, isto é, o(s) compositor(es) do salmo recolhe(m) os argumentos apresentados, todos muito justos, e, não podendo tratá-los como injustos, contorna(m)-(n)os pela mais "sombria e sinistra" argumentação teológicopsicológica: não ir a Jerusalém trás um sério risco. Por mais que justas sejam as razões para isso, não fazer a peregrinação a Jerusalém pode ofender Yahweh, que, ofendido, pode retribuir com casas arruinadas, em vez de casas construídas, cidades assoladas, em lugar de cidades protegidas, colheitas perdidas, ventres secos, onde se haveria de esperar farto pão e farto ventre...

Pode-se aplicar a chave a cada uma das seções do salmo. Tanto a cada uma de suas partes quanto ao todo. A cidade está sob a ameaça de bandoleiros vistos na região? Já se tem notícia de vilas próximas e campos atacados por bandos de desordeiros? Compreende-se a necessidade de intensificar os cuidados com a segurança da cidade, e o próprio Yahweh há de fazê-lo, porque é ele quem guarda a cidade, e não as sentinelas. Agora, se, porque julga que é ele quem vigia, o peregrino não vai a Jerusalém, para poder vigiar a cidade, quem sabe Yahweh há de ficar ofendido com a ofensa e decida não mais vigiar a cidade, de sorte que, inúteis, as sentinelas e nada sejam a mesma coisa, e o temor de que a cidade seja atacada converta-se em fato inexorável? Não é mais prudente ir a Jerusalém, e ter garantida a proteção de Yahweh? Yahweh satisfeito, cidade protegida. Yahweh insatisfeito, cidade desprotegida, com sentinela e tudo...

Terceira seção: é claro que a época da colheita é importante. Os grãos não serão colhidos por eles mesmos. Alguém tem de colhê-los. Como perder uma semana de viagem a Jerusalém? Mas vejam que, desde Jerusalém, é Yahweh quem colhe os grãos, é Yahweh quem faz o pão, e é Yahweh quem o dá aos seus amados, enquanto eles dormem. Logo, tanta preocupação chega a ser ofensiva. Pior ainda se a preocupação se converte em razão para não ir a casa daquele que dá o pão. E se ele se ofende? E se, ofendido Yahweh, da pior maneira possível, o peregrino 
descobre que, a despeito de ele trabalhar duro, arduamente, é Yahweh quem de fato planta, colhe e alimenta, ou, pelo menos, era...?

Finalmente, aquilo que aqui se interpreta como uma ameaça muito específica ocupa metade das dimensões do salmo. É muito justo que o peregrino esteja exultante de alegria. A chegada de mais um filho na casa é a prova de que as bênçãos de Yahweh pousam sobre ela, sobre aquela que dá à luz naquela casa, sobre aquele ventre fértil. Tais bênçãos são fundamentais para além da alegria com que a casa se enche: os filhos são a garantia de que o pai da casa não será jamais envergonhado durante os litígios com outros cidadãos na porta da cidade, porque um querelante que chega, sem as bênçãos férteis de Yahweh, o que se traduz numa família mirrada e numericamente insignificante, não há de ser páreo para o homem abençoado por Yahweh, que precisará de um considerável espaço na porta da cidade, para que seus filhos, numerosos, perfilem-se diante do ancião, pelo menos enquanto a desgraça não atingir aquela casa, e se forem os vivos, ou a mão abençoadora de um Yahweh decepcionado com a falta de reconhecimento por parte de seu amado, que não o vai honrar em seu templo, se retire de sobre aquele ventre, que seca, murcha e fenece... Weiser estava certo: “o tríplice 'em vão' (...) soa um tanto sombrio e sinistro" (WEISER, 1994, p. 596).

Se o exercício eventualmente parecer inadequado a alguém, talvez conviesse consultar o experimento hermenêutico que o já tantas vezes citado Kraus faz com um dos salmos que abrem a coleção dos "Cânticos das Subidas". Está-se agora diante de outra obra do comentarista, que, em determinado momento, afirma que “a cerimônia cultual de despedida se reflete em Sl 121 e culmina na seguinte afirmação: 'Yahweh guarda a tua saída e entrada agora e para sempre' (Sl 121,8)” (KRAUS, 1996, p. 134). Em sua interpretação do Salmo 121, Kraus transita entre a composição e o desempenho do peregrino, e situa a leitura que fez a partir da ótica do romeiro: "um participante do culto se despede do santuário" (KRAUS, 1996, 134), e, tendo diante de si a perspectiva da longa viagem de retorno, que lhe custará dias inteiros, precisa receber garantias de proteção e cuidado: "o meu auxílio me vem de Yahweh, que fez os céus e a terra” (KRAUS, 1996, p. 134), auxílio esse que 
resultará no fato de que "durante o caminho o pé não resvalará em perigo algum" (KRAUS, 1996, p. 134). Para Kraus, o Salmo 121 tem a função de promover a certeza subjetiva do "peregrino" de "Jerusalém" (KRAUS, 1996, p. 134). Ora, devese perguntar por que Kraus operou o trânsito retórico-hermenêutico entre a plástica do Sl 121 e o desempenho processional do peregrino que se instrumentaliza da canção, mas não fez o mesmo com o Salmo 127. Se, de um lado, a redação do Salmo 121 favorece o vínculo entre a composição e o contexto da peregrinação, por outro lado, como se viu, a posição quiástica central do Salmo 127 deveria impedir que o intérprete desviasse o olhar do mesmo contexto pragmático a que se destina esse único salmo "de Salomão". Acrescente-se ainda o fato de que Kraus não estabelece trânsito retórico apenas entre o Salmo 121 e o contexto extratextual da peregrinação. Ele o faz igualmente com outro salmo da mesma coleção, o 122: “já se postam nossos pés em tuas portas, Jerusalém' (Sl 122,2). Ao longo de todo o caminho de peregrinação ressoavam os cantos criados para tal eventualidade" (KRAUS, 1996, p. 100; MONLOUBOU, 1996, p. 70), e já mesmo no “momento de começar a viagem de peregrinação (...). Ó, que alegria quando me disseram: "vamos à casa de Yahweh' (Sl 122,1)" (KRAUS, 1996, p. 100). O exercício que se vem de fazer não é outro tipo de leitura que a que o próprio Kraus fez dos Salmos 121 e 122, conquanto, de minha parte, confessadamente marcado por aquela percepção de Weiser de que haja algo de "sombrio e sinistro" no Salmo 127.

\section{Conclusão}

O Salmo 127 ocupa o centro estrutural da coleção dos "Cânticos das Subidas" (Salmos 120-134). Essa posição se evidencia pelo fato de que os quinze salmos são distribuídos em série, recebendo todos eles o título "cântico das subidas", tendo os organizadores da coleção marcado especialmente quatro desses quinze salmos com títulos estruturantes, "de Davi”, formando programaticamente duas molduras superiores e duas molduras inferiores, no centro da qual, tendo recebido o único título "de Salomão", encontra-se o Salmo 127. O esquema foi impresso na seção "o Salmo 127 fora do contexto dos Salmos 120-134”. 
Esse conjunto concreto de elementos impõe que ao menos seja levantada a questão de se, nesse caso, tanto o título especial, "de Salomão", quanto o fato de ter sido colocado no centro da coleção dos cânticos das romarias a Jerusalém, não apontariam para a programática leitura contextual da composição: o Salmo 127 fala diretamente ao contexto da romaria. Assume-se que sim.

Tendo-se assumido que o contexto da romaria deve ser tomado como chave hermenêutica do Salmo 127, considerou-se o fato de que as quatro assertivas da composição tratam de potenciais razões para um peregrino escusar-se de participar da procissão. Os casos alegados são todos considerados muito justos, e, a despeito da redação sacerdotal da composição, eles não são refutados: construção da casa da família (v. 1a), proteção da cidade (1b), colheita dos grãos (v. 2) e recepção de um novo filho na casa (v. 3-5) são, de fato, preocupações muito legítimas e razões compreensíveis para postergar-se a peregrinação.

A estratégia retórica do salmo é não negar a validade dos argumentos, mas alertar ao peregrino que seu raciocínio está, além de equivocado, incorrendo em grave risco. Equivocado, porque o peregrino considera que as coisas que precisam efetivamente ser feitas, é ele quem as faz, quando, a rigor, e para o que realmente importa, é Yahweh. E em risco, porque, alegando ter de fazer o que na verdade é Yahweh que faz, o peregrino corre o risco de não ir a Jerusalém, e desta forma, também risco de ofender a divindade abençoadora que, por força da ofensa, deixe de fazer o que até então tem feito. O Salmo 127 constitui uma peça teológicopsicológica de convencimento de peregrinos a participarem da romaria a Jerusalém, por meio do recurso de alertá-los do perigo de ofenderem Yahweh com sua ausência e, assim, invocarem sobre si não as bênçãos do deus do templo, mas a supressão de todas as bênçãos futuras, e, até, as já concedidas. Weiser estava certo: tudo muito sombrio. Tudo muito sinistro. 


\section{REFERÊNCIAS}

AGOSTINHO. Comentários aos Salmos. Salmos 101-15O. São Paulo: Paulus, 1998.

ALONSO-SCHÖKEL, L. Orar com os Salmos. Grande sinal, São Paulo, v. 70, n. 6, p. 717$721,1998$.

ALONSO-SCHÖKEL, L; CARNITI, C. Salmos. Salmos 73-15O. São Paulo: Paulus, 1996.

BOSMA, C. J. Discernindo as vozes nos salmos: uma discussão de dois problemas na interpretação do Saltério. Fides Reformata, São Paulo, v. 9, n. 2, p. 75-118, 2004.

BRUEGgemanN, W; BELlinger, W. H. Psalms. New York: Cambridge Press, 2014.

CHOURAQUI, A. A Bíblia. Louvores II (Salmos). Rio de Janeiro: Imago, 1998.

DA SILVA, V. Os Salmos como literatura. RIBLA, Petrópolis, v. 2, n. 45, p. 9-23, 2003.

DAHLBERG, B. K. An exegetical study of Psalm 127. Master of Theology Dissertation. Wenham: Gordon College, 2007.

DECLAISSE-WALFORD, N.; JACOBSON, R. A.; TANNER, B. L. The Book of Psalms. Grand Rapids e Cambridge: Wm. B. Eerdmans, 2014.

FARIA, J. de F. O Livro de Salmos em seu contexto literário. RIBLA, Petrópolis, n. 52, v. 3, p. 11-28, 2005.

FERNANDES, L. A. A família conduzida pela Palavra de Deus. Salmo 127. In:

FERNANDES, L. A.; GRENZAR, M. Dança, ó terra! Interpretando salmos. São Paulo: Paulinas, 2013. p. 215-245.

KIDNER, D. Salmos 73-150. Introdução e comentário. São Paulo: Mundo Cristão, 2000.

KRAUS, H.-J. Los Salmos 1-59. Salamanca: Sígueme, 2009.

KRAUS, H.-J. Los Salmos 6o-150. Salamanca: Sígueme, 2014.

KRAUS, H-J. Teologia de los Salmos. Salamanca: Sígueme, 1996.

KUNTZ, J. K. The canonical wisdom Psalms of the Ancient Israel. Their rethoric, thematic and formal dimensions. In: JACKSON, J. J.; KESSLER, M. Rhetorical criticism. Essays in honor of James Muilemburg. Eugene: Pickwick, 1974. p. 186-222.

MCCANN, J. C. Book of Psalms. In: KECK, L. E. et al. The new interpreter's Bible. Nashville: Abingdom Press, 1996. v. 4.

MILLER, P. D. Psalm 127. The house of Yahweh built. JSOT, Sheffield, n. 22, p. 119-132, 1982.

MONLOUBOU, L. Os Salmos. In: MONLOUBOU, L. et al. Os Salmos e outros escritos. São Paulo: Paulus, 1996. p. 13-100. 
PHILLIPS, J. Exploring Psalms: an expository commentary. Grand Rapids: Kregel Publications, 2002. v. 2.

SOUZA, M. de B. Cantar ao Senhor numa terra de exclusão. Leitura dos Salmos a partir do cativeiro. Estudos Bíblicos, Petrópolis, n. 43, p. 20-29, 1994.

STOCKS, S. P. The Form and Function of the Tricolon in the Psalms of Ascents: Introducing a new paradigm for a Hebrew poetic line-form. Eugene: Pickwick, 2012.

USARSKI, F. História da Ciência da Religião. In: PASSOS, J. D.; USARSKI, F. (Org.). Compêndio de Ciência da Religião. São Paulo: Paulinas, 2013. p. 51-61.

WEISER, A. Os Salmos. São Paulo: Paulus, 1994.

ZORN, W. D. Psalms. Missouri: College Press, 2004. v. 2. 